\title{
The long-term outcomes of transcanalicular diode laser- assisted endoscopic dacryocystorhinostomy in isolated nasolacrimal duct obstruction
}

\author{
(1) Mehmet Cem Sabaner ${ }^{1}$, (1) Orhan Kemal Kahveci ${ }^{2}$, (1) Reşat Duman ${ }^{3}$,(1) Mehmet Akif Erol ${ }^{4}$, (1) Ersan Çetinkaya ${ }^{5}$, \\ (1)Kenan Yiğit ${ }^{5}$, (1) Güliz Fatma Yavaş ${ }^{6}$, (1) Rahmi Duman ${ }^{7}$
}

1 Samsun Bafra State Hospital, Clinic of Ophthalmology, Samsun, Turkey

${ }^{2}$ Afyonkarahisar Health Sciences University Faculty of Medicine, Department of Otorhinolaryngology, Afyonkarahisar, Turkey

${ }^{3}$ Bakircay University, Cigli Training and Research Hospital, Clinic of Ophthalmology, Izmir, Turkey

${ }^{4}$ Osmangazi University Faculty of Medicine, Department of Ophthalmology, Eskisehir, Turkey

5University of Health Sciences Turkey, Antalya Training and Research Hospital, Clinic of Ophthalmology, Antalya, Turkey

6 Hacettepe University Faculty of Medicine, Department of Ophthalmology, Ankara, Turkey

7Dunya Goz Hospital, Clinic of Ophthalmology, Ankara, Turkey

\section{Date submitted:}

23.07.2020

Date accepted:

28.12.2020

Online publication date:

15.09.2021

\section{Corresponding Author:}

Mehmet Cem Sabaner, M.D.,

Bafra State Hospital, Clinic of

Ophthalmology, Samsun, Turkey

drmcemsabaner@yahoo.com

ORCID:

orcid.org/0000-0002-0958-9961

Keywords: Adult,

dacryocystorhinostomy, epiphora, laser therapy, nasolacrimal duct obstruction

Presented in: The manuscript was accepted as an oral presentation in the Turkish Ophthalmology Society $51^{\text {st }}$ National Ophthalmology Congress 2017 by Rahmi Duman. The study was conducted at the Department of Ophthalmology, Afyon Kocatepe University, Afyon, Turkey.

\section{ABSTRACT}

Aims: To evaluate the long-term surgical success of transcanalicular dacryocystorhinostomy (TCDCR) with diode-laser in the treatment of epiphora due to isolated naive nasolacrimal duct obstruction (NLDO) in adults.

Methods: This retrospective study included patients with isolated naive NLDO, who underwent diode laser-assisted TCDCR. No patients had pathology in the nasal region detected by an otorhinolaryngologist. The included patients had documented information about epiphora evaluation with lacrimal system irrigation with fluorescein dye, and annual direct imaging of osteotomy patency with nasal endoscopy. Success was defined as no postoperative epiphora, conjunctivitis or dacryocystitis, an open passage in the lacrimal system lavage, and patient satisfaction.

Results: The study included 116 patients [mean age: $49.6 \pm 11.4$ years, female: 67 (57.8\%)]. The success rate was $84.5 \%$ in the first year, $80.2 \%$ in the second year, and $76.7 \%$ in the third year. Following the operation, $9(7.8 \%)$ patients had epiphora, $8(6.9 \%)$ patients were not satisfied, and $1(0.8 \%)$ patient developed conjunctivitis/dacryocystitis in the first year. Three (2.6\%) patients had dissatisfaction and $2(1.7 \%)$ patients had the complaints of epiphora correlated with nasolacrimal lavage obstruction in the second year. Two (1.7\%) patients were dissatisfied and $2(1.7 \%)$ patients had epiphora complaints confirmed with nasolacrimal lavage in the third year.

Conclusions: The present study showed that the treatment of epiphora due to isolated NLDO with diode laser-assisted TCDCR can provide long-term success in major outcomes in adult patients. 


\section{Introduction}

The nasolacrimal duct (NLD) is a two-sided structure that carries the tear from the lacrimal sac to the nasal cavity at the level of the lower concha, located beneath the lower fold of the nasal cavity. The NLD obstruction can cause epiphora, conjunctivitis or dacryocystitis. While it usually does not cause visual impairment, it affects the quality of life due to epiphora. NLD obstruction is more common in middle-aged women than in men (1).

While medical treatment is tried primarily in acute NLD obstruction, surgical procedures come to the fore in chronic occlusions. In surgery, dacryocystorhinostomy (DCR), which is the process of creating a permanent new path between the lacrimal sac and nasal mucosa, is performed. The first externally performed DCR surgery was described by Toti et al. (2) in 1904, and today's classic external DCR technique was developed in 1971 with nasal and lacrimal mucosal flap suturing $(3,4)$. Due to the disadvantages of external skin surgeries due to scar formation, excessive bleeding, the need for general anesthesia and the long duration of the operation, internal surgeries applied with the help of modern technology have come to the fore. Laser application for the first time in DCR surgery was started by Massaro et al. (5) with cadaver studies using Blue-Green Argon laser, and then entered clinical practice by Reifler (6) in 1993 with KTP (potassium titanyl phosphate) laser. In the following years, Excimer laser (308 NM), $\mathrm{CO}_{2}$ laser (10600 NM), YAG laser, Nd: YAG (neodymium: yttrium, aluminum, garnet, $1064 \mathrm{NM}$ ) laser applications and balloon catheter dilation, silicone intubation, endonasal DCR, laser-assisted endonasal DCR procedures are also applied methods (7). Endoscopic DCR surgery with diode laser was performed for the first time by Eloy et al. (7) in 2000, and it is the most widely used laser procedure by transcanalicular method because of the most satisfying results in them. We aim to evaluate the long-term success of our transcanalicular diode laser-assisted endoscopic DCR (TCDCR) surgeries.

\section{Methods}

This retrospective study included patients with isolated naive NLDO, who underwent diode laser-assisted TCDCR. Ethical approval was obtained by the Afyonkarahisar University of Health Sciences Local Clinical Research Ethics Committee (approval number: 2018/3 2011-KAEK-2, date: 02.03.2018). The included patients had documented information about epiphora evaluation with lacrimal system irrigation with fluorescein dye, and annual direct imaging of osteotomy patency with nasal endoscopy. Whole patients had been diagnosed with isolated naive NLDO with lacrimal canal irrigation, afterward, had undergone TCDCR surgery between 2014 and 2017. The following exclusion criteria were applied: 1) The presence of any nasal pathology (intranasal synechiae, intranasal polyp, septum deviation, and concha bullosa, etc.) detected by otorhinolaryngology, 2) Having a history of having undergone any ocular or nasal surgery, 3) Having a history of smoking, 4) Having a systemic disease 5) History of any type of regular medicine use, 6) Being under 40 and over 70 years old, 7) Having bicanalicular silicone tube that cannot be intubated, and 8) Having silicone tubes that were removed before three months for any reason. Nasal endoscopy had been performed by the same otorhinolaryngology specialist physician (OKK) before the operations.

Patients' epiphora evidence, satisfaction, attack of conjunctivitis, or dacryocystitis information were taken from the patient files. According to the information obtained from these files, success was defined as no postoperative epiphora, conjunctivitis or dacryocystitis, an open passage in the lacrimal system lavage, and expression of patient's satisfaction when questioned in comparison of the preoperative and postoperative status. In the opposite situations were considered unsuccessful.

All surgeries had been performed by the same surgical team (RD, RD, OKK) under general anesthesia. After surgery, netilmicin and dexamethasone-containing eye drop (4x1), and $0.025 \%$ flunisolide nasal spray treatment had been given for three weeks $(3 \times 2)$, and oral amoxicillin-clavulanate $1000 \mathrm{mg}$ (2x1) had been given for one week. Patients had been followedup on the $1^{\text {st }}$ day, $1^{\text {st }}$ week, $1^{\text {st }}$ month, $2^{\text {nd }}$ month, and afterward periods in three-month and annual periods after surgery. These follow-up data were taken from their patient files. All examinations and follow-ups of the patients had been performed by the same researchers (MCS, RD, and OKK). No postoperative period complication had been observed. Silicone tubes had been removed after three months with an otorhinolaryngology specialist, by performing an endoscopic examination.

\section{Statistical Analysis}

Statistical analysis was performed using Statistical Package for the Social Sciences (SPSS) software, version 22.0 (IBM SPSS, Chicago, IL, USA). Descriptive statistical methods (mean, standard deviation) were used in the evaluation of the data. Data were analyzed for distribution by the Shapiro-Wilk test for normality analysis. The non-parametric McNemar test was used to compare consecutive samples that did not fit the normal distribution. The evaluations were made at the $95 \%$ confidence interval, and the $p$ values of less than 0.05 were considered statistically significant.

\section{Results}

The total number of patients evaluated was 165 , and 116 patients were included in the study following exclusions. The

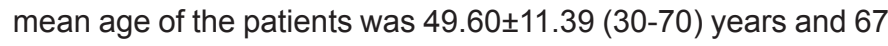
$(57.8 \%)$ of the patients were female (Table 1$)$. No complication developed intraoperatively in any patient.

The comparisons of the consecutive evaluations are shown in Table 2. The success rate for our criteria was found to be $84.5 \%$ (98 patients) in the first year, $80.2 \%$ in the second year, and $76.7 \%$ (89 patients) after the three years. 
When 116 patients were evaluated for causes of unsuccess by years; in the first year $(15.5 \%)$, nine patients $(7.8 \%)$ had complaints of epiphora, eight patients $(6.9 \%)$ had dissatisfaction, and one patient $(0.8 \%)$ developed conjunctivitis/dacryocystitis attack (Figure 1). At the end of the second year (19.8\%), in addition to the first year, three patients $(2.6 \%)$ had dissatisfaction and two patients $(1.7 \%)$ had complaints of epiphora. At the end of the third year $(23.3 \%)$, in addition to the past two years, two patients $(1.7 \%)$ had dissatisfaction and two patients $(1.7 \%)$ had complaints of epiphora verified with nasolacrimal lavage obstruction.

Patients with obstruction in nasolacrimal canal lavage were considered to have a recurrence. The mean recurrence time in patients during the follow-ups was $16.52 \pm 6.94$ months. Patients who had a recurrence and wanted to undergo surgery were reoperated with TCDCR, and most of them were found to have occlusion at the ostium level.

\begin{tabular}{|c|c|}
\hline & Patients $(n=116)$ \\
\hline Age (year) & $49.6 \pm 11.4$ \\
\hline Male:female ratio & 49:67 \\
\hline Laterality (right/left) & $51 / 65$ \\
\hline
\end{tabular}

\begin{tabular}{|c|c|c|c|}
\hline \multirow[b]{2}{*}{ Total cases $(n=116)$} & \multicolumn{2}{|l|}{ Success } & \multirow[b]{2}{*}{ p value* } \\
\hline & $\begin{array}{l}\text { Number } \\
\text { of } \\
\text { patients }\end{array}$ & $\begin{array}{l}\text { Rate } \\
(\%)\end{array}$ & \\
\hline End of the first year & 98 & 84.5 & $<0.001$ \\
\hline End of the second year & 93 & 80.2 & $<0.001(0.063)^{\mathrm{a}}$ \\
\hline End of the third year & 89 & 76.7 & $<0.001(0.125)^{\mathrm{b}}$ \\
\hline \multicolumn{4}{|c|}{$\begin{array}{l}\text { *: McNemar test results of the comparison of the evaluation results } \\
\text { immediately after surgery and at the end of each year. Immediate } \\
\text { postoperative, no patients had complaints of epiphora or closed nasolacrimal } \\
\text { canal lavage findings or conjunctivitis/dacryocystitis. }\end{array}$} \\
\hline \multicolumn{4}{|c|}{ a: Comparison of the evaluation results of the first and second year-end. } \\
\hline \multicolumn{4}{|c|}{ b: Comparison of the evaluation results of the second and third year-end. } \\
\hline
\end{tabular}

\section{Annual Analysis of Unsuccess}

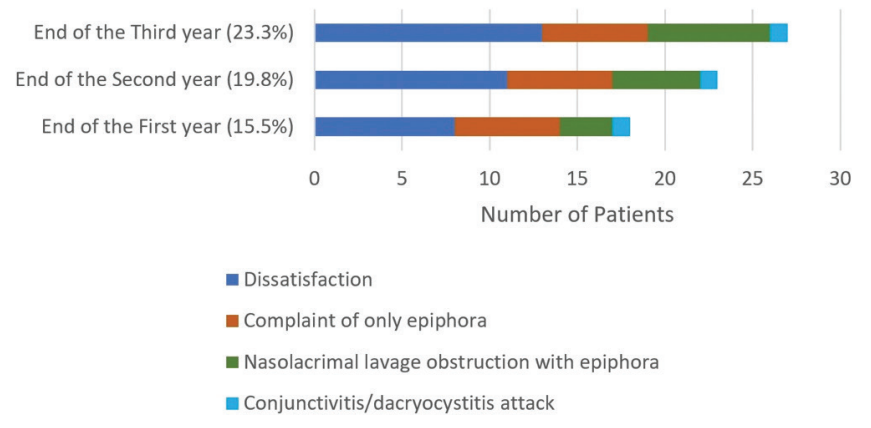

Figure 1. Annual analysis of unsuccess

\section{Discussion}

The external DCR surgery technique, which was first described in 1904 and developed in 1971, has been the gold standard treatment of chronic nasolacrimal duct obstruction for more than a hundred years $(8,9)$. The rate of success of external DCR surgery is $85-99 \%$ and is generally above $90 \%$ (10). While the transnasal DCR surgery has a success rate of $80-85 \%$, it has been shown that this rate is $70-90.5 \%$ in TCDCR surgeries $(4,11,12)$. External DCR surgery results reported from Turkey has been quite satisfactory. It has been reported that approximately $90 \%$ and above anatomical and functional success have been achieved (13-15). Even good results have been reported in bilateral simultaneous surgeries $(16,17)$. In the first studies reported with diode laser TCDCR, Eloy et al. (7) and Haefliger and Piffaretti (18) achieved $65-80 \%$ success in their series (8). Shortly after these studies, Kaynak-Hekimhan et al. (19) reported $80 \%$ success in their TCDCR study.

Despite the high success rates of external DCR surgeries, due to the disadvantages of facial skin scar formation, excessive bleeding, requiring general anesthesia, and long operation and recovery period; internal surgeries performed endoscopically have come to the fore with the contribution of modern technology (20). With these internal surgery techniques, the continuity of the pump function of the lacrimal system can be achieved by leaving the medial canthal tendon intact (21). Studies that keep TCDCR success rate equal with external DCR are also noted. In the 244case wide series of Ajalloueyan et al. (22), success rates were found to be $92.6 \%$ in external DCR and $93.4 \%$ in TCDCR in an 18-month follow-up. In another study, the success rate was shown as $88 \%$ for TCDCR in a 36-month follow-up (12). Also, Drnovsek-Olup and Beltram (4) suggested that TCDCR surgery may be repeated in case of recurrence in obstruction of the NLD. Similarly, we had the chance to successfully re-operate in our recurrent cases. In this study, surgical success was determined in 116 patients' satisfaction and follow-up evaluation results, and an annual evaluation was made according to the information obtained from patient files. In this method, the success rate was $84.5 \%$ in the first year, $80.2 \%$ in the second year, and $76.7 \%$ in the third year. In our operations, keeping the aspirator between the concha and the mucosa, protecting the middle concha mucosa from laser or mechanical damage, not leaving the necrotized tissue caused by laser around the ostium, and placing a sponge between the concha and the rhinostomy to prevent the development of synechiae at the end of the operation may have affected our success rates (Figure 2). Similar precautions during the operation may reduce intranasal inflammation and reduce postoperative adhesions and protect the concha (23). Postoperative nasolacrimal lavage was performed to remove residues in the pathway. There are opinions that the tissue residues reduce the passage of the opened path (23). 


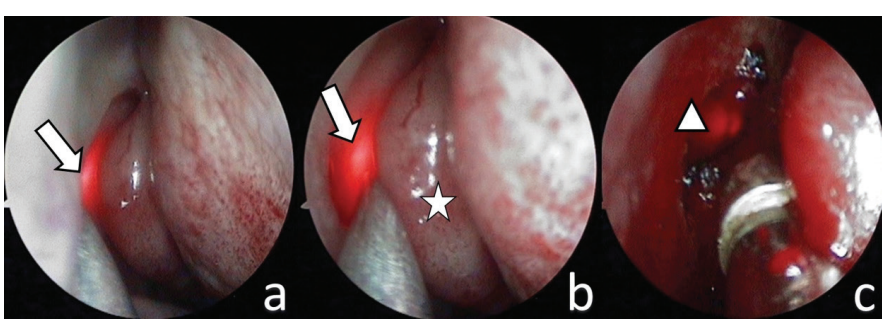

Figure 2. Transcanalicular diode laser-assisted endoscopic dacryocystorhinostomy, a: Appearance the fiberoptic probe light (arrow), b: Gently deviating the concha (star) from the probe light (arrow) with Frazier suction aspirator tube, c: Providing ostium (arrow-head) patency by laser treatment, and tissue residues cleaning with Blakesley nasal forceps

TCDCR surgeries can be performed under local and general anesthesia (24). In operations performed with local anesthesia, patients feel pain and manipulations during the operation, and this makes the operation difficult. Therefore, general anesthesia is usually used in these surgeries. In this study, whole patients had undergone TCDCR surgery under general anesthesia without any complication in terms of general anesthesia.

The main strengths of this study are the regular follow-up of patients in patient files, organization of patient files by the same physicians, and successful completion of surgeries under general anesthesia without complications with the same surgical team.

The limitations of the study are the retrospective design, exclusion of patients with nasal pathology from the study, giving personal and subjective answers in terms of patient satisfaction, and exclusion of patients without bicanalicular silicone tube intubation from the study. The inclusion of only patients with isolated and NLDO may have affected the study results. Therefore, when the study groups specified in the limitations are added to the study, the results of the study may change, and prospective researches are needed.

\section{Conclusion}

In conclusion, this study has showed that laser-assisted endoscopic TCDCR can be used for long-term outcomes of treatment in epiphora in adults due to isolated nasolacrimal duct obstruction. Further studies are needed.

\section{Acknowledgments}

Specials thanks to operating room nurses for supporting surgeries, and to Hasan Nadir Rana (Public health expert, MD; Biostatistics, MSc) for helping with the statistical analysis section.

\section{Ethics}

Ethics Committee Approval: Ethical approval was obtained by the Afyonkarahisar University of Health Sciences Local Clinical Research Ethics Committee (approval number: 2018/3 2011-KAEK-2, date: 02.03.2018).
Informed Consent: Retrospective study.

Peer-review: Externally peer-reviewed.

\section{Authorship Contributions}

Surgical and Medical Practices: M.C.S., O.K.K., R.D., M.A.E., E.Ç., K.Y., G.F.Y., R.D., Concept: M.C.S., O.K.K., R.D., M.A.E., E.Ç., K.Y., G.F.Y., R.D., Design: M.C.S., O.K.K., R.D., M.A.E., E.Ç., K.Y., G.F.Y., R.D., Data Collection or Processing: M.C.S., M.A.E., R.D., Analysis or Interpretation: M.C.S., M.A.E., R.D., Literature Search: M.C.S., M.A.E., R.D., Writing: M.C.S., O.K.K., R.D., M.A.E., E.Ç., K.Y., G.F.Y., R.D.

Conflict of Interest: No conflict of interest was declared by the authors.

Financial Disclosure: The authors declared that this study received no financial support.

\section{References}

1. Park JH, Huh JA, Piao JF, Lee H, Baek SH. Measuring nasolacrimal duct volume using computed tomography images in nasolacrimal duct obstruction patients in Korean. Int J Ophthalmol. 2019;12:100-105.

2. Toti A, Karadag O, Arikan S, et al. Nuovo metodo conservatoire di cura radicale delle suppurazioni croniche del sacco lacrimale (dacriocistorinostomia). Clin Mod Pisa. 1904;1:385-387.

3. Doğan M, Alizada A, Yavaş GF, Kahveci OK, Bakan O. Laser-assisted dacryocystorhinostomy in nasolacrimal duct obstruction: 5-year follow-up. Int J Ophthalmol. 2018;11:1616-1620.

4. Drnovsek-Olup B, Beltram M. Transcanalicular diode laserassisted dacryocystorhinostomy. Indian J Ophthalmol. 2010;58:213-217.

5. Massaro BM, Gonnering RS, Harris GJ. Endonasal laser dacryocystorhinostomy. A new approach to nasolacrimal duct obstruction. Arch Ophthalmol. 1990;108:1172-1176.

6. Reifler DM. Results of endoscopic KTP laser-assisted dacryocystorhinostomy. Ophthalmic Plast Reconstr Surg. 1993;9:231-236.

7. Eloy P, Trussart C, Jouzdani E, Collet S, Rombaux $\mathrm{P}$, Bertrand B. Transcanalicular diode laser assisted dacryocystorhinostomy. Acta Otorhinolaryngol Belg. 2000;54:157-163.

8. Athanasiov PA, Prabhakaran VC, Mannor G, Woog JJ, Selva D. Transcanalicular approach to adult lacrimal duct obstruction: a review of instruments and methods. Ophthalmic Surg Lasers Imaging. 2009;40:149-159.

9. Alañón Fernández FJ, Alañón Fernández MA, Martínez Fernández A, Cárdenas Lara M. Dacriocistorrinostomía transcanalicular con láser diodo [Transcanalicular dacryocystorhinostomy technique using diode laser]. Arch Soc Esp Oftalmol. 2004;79:325-330. 
10. Saiju R, Morse LJ, Weinberg D, Shrestha MK, Ruit $\mathrm{S}$. Prospective randomised comparison of external dacryocystorhinostomy with and without silicone intubation. Br J Ophthalmol. 2009;93:1220-1222.

11. Hong JE, Hatton MP, Leib ML, Fay AM. Endocanalicular laser dacryocystorhinostomy analysis of 118 consecutive surgeries. Ophthalmology. 2005;112:1629-1633.

12. Plaza G, Beteré F, Nogueira A. Transcanalicular dacryocystorhinostomy with diode laser: long-term results. Ophthalmic Plast Reconstr Surg. 2007;23:179-182.

13. Erdöl H, Akyol N, Imamoglu HI, Sözen E. Long-term followup of external dacryocystorhinostomy and the factors affecting its success. Orbit. 2005;24:99-102.

14. Akcay E, Yuksel N, Ozen U. Revision External Dacryocystorhinostomy Results After a Failed Dacryocystorhinostomy Surgery. Ophthalmol Ther. 2016;5:75-80.

15. Buttanri IB, Buttanri B, Serin D. Outcome of External Dacryocystorhinostomy and Monocanalicular Intubation in Patients with Total Obstruction of One Canalicus. Korean J Ophthalmol. 2019;33:138-141.

16. Yazici B, Akova B. Simultaneous bilateral external dacryocystorhinostomy. Acta Ophthalmol Scand. 2007;85:667-670.

17. Yuksel D, Kosker M, Akoz I, Simsek S. Long-term results of simultaneous bilateral external dacryocystorhinostomy in cases with bilateral dacryostenosis. Semin Ophthalmol. 2015;30:20-24.
18. Haefliger IO, Piffaretti JM. Lacrimal drainage system endoscopic examination and surgery through the lacrimal punctum. Klin Monbl Augenheilkd. 2001;218:384-387.

19. Kaynak Hekimhan P, Çelikoyar M, Göker S, Yilmaz ÖF. Endoscopic Laser Dacryocystorhinostomy (EL-DCR). Turk J Ophthalmol. 2002;32:332-336.

20. Eroğul Ö, Eryiğit Eroğul L, Doğan M, Polat O, Buyruk A. Comparison of External Dacryocystorhinostomy and Transcanalicular Multidiod Laser Dacryocystorhinostomy Results in Patients with Acquired Nasolacrimal Duct Obstruction. Acta Medica Alanya. 2017;1:67-71.

21. Malhotra R, Wright M, Olver JM. A consideration of the time taken to do dacryo-cystorhinostomy (DCR) surgery. Eye (Lond). 2003;17:691-696.

22. Ajalloueyan $\mathrm{M}$, Fartookzadeh $\mathrm{M}$, Parhizgar $\mathrm{H}$. Use of laser for dacrocystorhinostomy. Arch Otolaryngol Head Neck Surg. 2007;133:340-343.

23. Tripathi A, Lesser TH, O'Donnell NP, White S. Local anaesthetic endonasal endoscopic laser dacryocystorhinostomy: analysis of patients' acceptability and various factors affecting the success of this procedure. Eye (Lond). 2002;16:146-149.

24. Riad W, Chaudhry IA. Anaesthesia for dacryocystorhinostomy. Curr Anaesth Crit Care. 2010;21:180-183. 